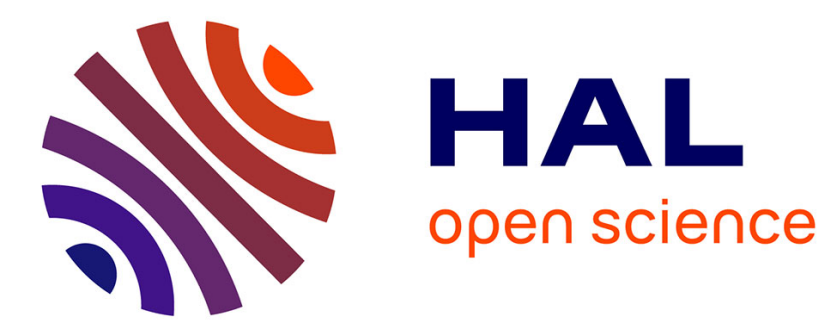

\title{
A hemodynamic study of pulmonary hypertension in sickle cell disease.
}

Florence Parent, Dora Bachir, Jocelyn Inamo, François Lionnet, Françoise

Driss, Gylna Loko, Anoosha Habibi, Soumiya Bennani, Laurent Savale, Serge Adnot, et al.

\section{To cite this version:}

Florence Parent, Dora Bachir, Jocelyn Inamo, François Lionnet, Françoise Driss, et al.. A hemodynamic study of pulmonary hypertension in sickle cell disease.. New England Journal of Medicine, 2011, 365 (1), pp.44-53. 10.1056/NEJMoa1005565 . inserm-00609555

\section{HAL Id: inserm-00609555 https://www.hal.inserm.fr/inserm-00609555}

Submitted on 19 Jul 2011

HAL is a multi-disciplinary open access archive for the deposit and dissemination of scientific research documents, whether they are published or not. The documents may come from teaching and research institutions in France or abroad, or from public or private research centers.
L'archive ouverte pluridisciplinaire HAL, est destinée au dépôt et à la diffusion de documents scientifiques de niveau recherche, publiés ou non, émanant des établissements d'enseignement et de recherche français ou étrangers, des laboratoires publics ou privés. 


\title{
A Hemodynamic Study of Pulmonary Hypertension in Sickle Cell Disease
}

\author{
Florence Parent, M.D., Dora Bachir, M.D., Jocelyn Inamo, M.D., \\ François Lionnet, M.D., Françoise Driss, M.D., Gylna Loko, M.D., \\ Anoosha Habibi, M.D., Soumiya Bennani, M.D., Laurent Savale, M.D., \\ Serge Adnot, M.D., Bernard Maitre, M.D., Azzedine Yaïci, M.D., Leila Hajji, M.D., \\ Dermot S. O'Callaghan, M.D., Pierre Clerson, M.D., Robert Girot, M.D., \\ Frederic Galacteros, M.D., and Gerald Simonneau, M.D.
}

A BSTRACT

From Université Paris-Sud, Kremlin-Bicêtre (F.P., F.D., A.Y., D.S.O., G.S.); Hôpital Antoine Béclère (F.P., S.B., A.Y., D.S.O., G.S.) and INSERM Unité 999 (F.P., D.S.O., G.S.), Clamart; Hôpital Henri Mondor (D.B., A.H., L.S., S.A., B.M., L.H., F.G.) and INSERM Unité 955 (L.S., S.A., B.M.), Créteil; Hôpital La Meynard, Fort de France (J.I.); Hôpital Tenon, Paris (F.L., R.G.); Hôpital du Lamentin, Lamentin (G.L.); and Orgamétrie Biostatistiques, Roubaix (P.C.) - all in France. Address reprint requests to Dr. Simonneau at the Service de Pneumologie et Réanimation Respiratoire, Hôpital Antoine Béclère, AP-HP Université Paris-Sud, 157 rue de la porte de Trivaux, 92140 Clamart, France, or at gerald.simonneau@abc.aphp.fr.

N Engl J Med 2011;365:44-53.

Copyright (C) 2011 Massachusetts Medical Society.

\section{BACKGROUN D}

The prevalence and characteristics of pulmonary hypertension in adults with sickle cell disease have not been clearly established.

\section{METHODS}

In this prospective study, we evaluated 398 outpatients with sickle cell disease (mean age, 34 years) at referral centers in France. All patients underwent Doppler echocardiography, with measurement of tricuspid-valve regurgitant jet velocity. Right heart catheterization was performed in 96 patients in whom pulmonary hypertension was suspected on the basis of a tricuspid regurgitant jet velocity of at least $2.5 \mathrm{~m}$ per second. Pulmonary hypertension was defined as a mean pulmonary arterial pressure of at least $25 \mathrm{~mm} \mathrm{Hg}$.

\section{RESULTS}

The prevalence of a tricuspid regurgitant jet velocity of at least $2.5 \mathrm{~m}$ per second was $27 \%$. In contrast, the prevalence of pulmonary hypertension as confirmed on catheterization was $6 \%$. The positive predictive value of echocardiography for the detection of pulmonary hypertension was $25 \%$. Among the 24 patients with confirmed pulmonary hypertension, the pulmonary-capillary wedge pressure was $15 \mathrm{~mm} \mathrm{Hg}$ or less (indicating precapillary pulmonary hypertension) in 11 patients. Patients with confirmed pulmonary hypertension were older and had poorer functional capacity and higher levels of $\mathrm{N}$-terminal pro-brain natriuretic peptide than other patients. In contrast, patients who had a tricuspid regurgitant jet velocity of at least $2.5 \mathrm{~m}$ per second without pulmonary hypertension and patients with a tricuspid regurgitant jet velocity of less than $2.5 \mathrm{~m}$ per second had similar clinical characteristics.

\section{CONCLUSIONS}

In this study of adults with sickle cell disease, the prevalence of pulmonary hypertension as confirmed on right heart catheterization was 6\%. Echocardiographic evaluation alone had a low positive predictive value for pulmonary hypertension. (Funded by the French Ministry of Health and Assistance Publique-Hôpitaux de Paris; ClinicalTrials.gov number, NCT00434902.) 


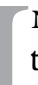

N SEVERAL STUDIES, PULMONARY HYPERtension, particularly pulmonary arterial hypertension, has been reported as a frequent complication of sickle cell disease. ${ }^{1-4}$ Pulmonary arterial hypertension is characterized by the presence of precapillary pulmonary hypertension in the absence of left-sided heart disease, lung disease, or chronic thromboembolism. On histopathological analysis, pulmonary arterial hypertension is characterized by the proliferation of medial smooth-muscle cells and endothelial cells in the small pulmonary arteries. ${ }^{5}$ Pulmonary arterial hypertension may be idiopathic, heritable, or associated with other disorders, such as connective tissue diseases and congenital heart disease. ${ }^{6}$ In the updated classification of pulmonary hypertension, sickle cell disease appears as a separate entity in the subgroup of cases of pulmonary arterial hypertension associated with identified diseases. $^{6-8}$

In recent studies involving adults with sickle cell disease, the prevalence of pulmonary hypertension (as defined by a tricuspid-valve regurgitant jet velocity of at least $2.5 \mathrm{~m}$ per second on Doppler echocardiography) has been as high as $30 \% .^{9-12}$ However, in these studies, the diagnosis of pulmonary hypertension was not systematically confirmed on right heart catheterization, a procedure that is recommended in international guidelines as the standard of care. ${ }^{7,8,13}$ In screening programs for pulmonary hypertension in highrisk populations, the use of a definition of pulmonary hypertension that is based on the results of echocardiography alone results in a substantial number of false positive diagnoses that are not confirmed on right heart catheterization. ${ }^{14-16}$ Hence, invasive hemodynamic assessment is necessary to accurately diagnose pulmonary hypertension. In some studies involving patients with sickle cell disease, a tricuspid regurgitant jet velocity of at least $2.5 \mathrm{~m}$ per second independently predicted an increased risk of death. ${ }^{9-11}$ However, the proportion of these patients with an abnormally high mean pulmonary arterial pressure is unknown. The use of right heart catheterization also makes it possible to distinguish between precapillary pulmonary hypertension, which is mainly caused by pulmonary arterial hypertension, and postcapillary pulmonary hypertension, which is associated with left-sided heart disease. ${ }^{4,6}$

The objective of this study was to determine the prevalence of pulmonary hypertension, as assessed on right heart catheterization, in adults with sickle cell disease in whom the disorder was suspected on the basis of Doppler echocardiography. We also sought to categorize pulmonary hypertension according to its cause.

\section{METHODS}

\section{STUDY DESIGN}

This prospective, multicenter study was performed in collaboration with three French referral centers for sickle cell disease and the National Reference Center for Pulmonary Hypertension. The study protocol was approved by the ethics committee at each participating center. The study was funded by the French Ministry of Health and the Delegation for Clinical Research of the Assistance Publique-Hôpitaux de Paris. The sponsors had no role in the design or conduct of the study. Data were collected by investigators at each study center.

\section{STUDY PATIENTS}

Patients with sickle cell disease who were 18 years of age or older were recruited from the three referral centers. All patients were homozygous for hemoglobin $S$ or had $S \beta^{0}$ thalassemia. Only outpatients in stable condition were included. Exclusion criteria were severe renal insufficiency, severe liver disease, and chronic restrictive lung disease (Fig. 1). All patients provided written informed consent. Details regarding the selection and evaluation of patients are provided in the Supplementary Appendix, available with the full text of this article at NEJM.org.

\section{ECHOCARDIOGRAPHY AND RIGHT HEART CATHETERIZATION}

We performed transthoracic echocardiography in all patients as a screening test for pulmonary hypertension. ${ }^{17-19}$ We used continuous-wave Doppler sampling of the peak tricuspid-valve regurgitant jet velocity to calculate the pulmonary arterial systolic pressure, as described previously. ${ }^{20-22}$ (For details, see the Supplementary Appendix.) We then performed right heart catheterization in all patients with a tricuspid regurgitant jet velocity of at least $2.5 \mathrm{~m}$ per second.

On the basis of the results of echocardiography and right heart catheterization, we classified patients into three groups (Fig. 1). Patients in group 1 had either a tricuspid regurgitant jet velocity of less than $2.5 \mathrm{~m}$ per second or a tricuspid regurgitant jet velocity that could not be measured, without other echocardiographic signs of 


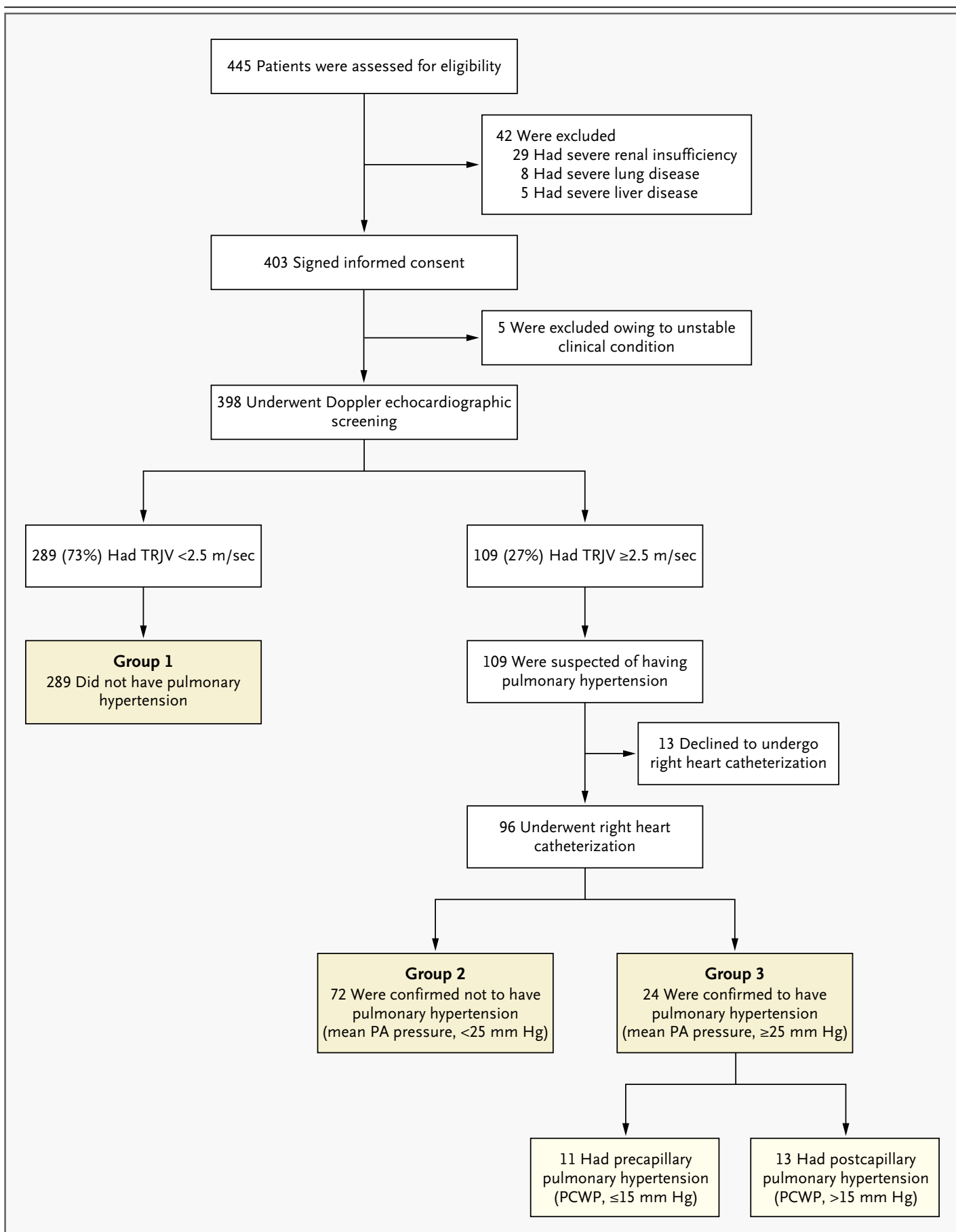

Figure 1. Enrollment and Outcomes.

PA denotes pulmonary artery, PCWP pulmonary-capillary wedge pressure, and TRJV tricuspid regurgitant jet velocity.

pulmonary hypertension or a decrease in the diffusion capacity for carbon monoxide corrected for alveolar volume. Patients in group 2 had a tricuspid regurgitant jet velocity of at least $2.5 \mathrm{~m}$ per second without confirmed pulmonary hyperten- sion on catheterization (mean pulmonary arterial pressure, $<25 \mathrm{~mm} \mathrm{Hg}$ ). Patients in group $3 \mathrm{had}$ a tricuspid regurgitant jet velocity of at least $2.5 \mathrm{~m}$ per second with confirmed pulmonary hypertension (mean pulmonary arterial pressure, 
$\geq 25 \mathrm{~mm} \mathrm{Hg}$ ). Patients in group 3 were further classified as having either precapillary pulmonary hypertension (pulmonary-capillary wedge pressure, $\leq 15 \mathrm{~mm} \mathrm{Hg}$ ) or postcapillary pulmonary hypertension (pulmonary-capillary wedge pressure, $>15 \mathrm{~mm} \mathrm{Hg}^{6}{ }^{6}$

\section{FOLLOW-UP}

We performed prospective follow-up evaluations with scheduled annual appointments with physicians for 3 years. For patients who died during follow-up, the date and cause of death were documented.

\section{STATISTICAL ANALYSIS}

We used Pearson's correlation coefficient to quantify the correlation between the estimation of systolic pulmonary arterial pressure on echocardiography and the measurement on catheterization. For intergroup comparisons, we used analysis of variance, Student's t-test, or the Wilcoxon test for continuous variables, depending on the number of groups for comparison and on the normality of the distribution. For categorical data, we used the chi-square test or Fisher's exact test, depending on the expected number of patients in each cell. To adjust for multiple comparisons, we performed post hoc Bonferroni tests for continuous variables. The type I error risk was partitioned for categorical variables (with a threshold of 0.025 for each comparison). For exploratory purposes, we performed a nonparametric classification and regression tree analysis $^{23}$ to evaluate the use of the 6-minute walk distance, the level of $\mathrm{N}$-terminal pro-brain natriuretic peptide (NT-proBNP), and the tricuspid regurgitant jet velocity as a means of selecting patients for right heart catheterization (for details, see the Supplementary Appendix). A P value of less than 0.05 was considered to indicate statistical significance for all tests other than the multiplecomparisons analysis.

RESULTS

\section{STUDY PATIENTS}

From February 2007 through March 2009, we evaluated 445 patients who met the predefined inclusion criteria (Fig. 1). Of these patients, 42 were excluded because of serious coexisting illnesses, and the remaining 403 patients consented to participate in the trial; 5 patients were subsequently excluded because of an unstable clinical condition. The remaining 398 patients underwent Doppler echocardiographic screening. Thirteen patients who were scheduled to undergo catheterization declined to participate. The baseline characteristics of the remaining 385 patients who were evaluated according to the study protocol are shown in Table 1. All 403 patients who provided consent were included in the follow-up analysis. The mean $( \pm S D)$ follow-up period was $26 \pm 6$ months and was similar for the three subgroups of patients.

\section{PREVALENCE OF PULMONARY HYPERTENSION}

Among the 398 patients who underwent echocardiography, 109 (27\%) had a peak tricuspid regurgitant jet velocity of at least $2.5 \mathrm{~m}$ per second (Fig. 1). Among the 96 patients who then underwent catheterization, 24 (25\%) had confirmed pulmonary hypertension. There was a significant correlation between the estimation of pulmonary arterial systolic pressure on echocardiography and measurement during catheterization (Fig. 2). However, the strength of this correlation was only moderate, as reflected in the correlation coefficient $(r=0.645)$.

\section{CHARACTERISTICS OF THE PATIENTS}

The characteristics of patients according to subgroup (as defined in the Methods section) are shown in Table 2. Patients in group 1 and group 2 were similar with respect to the frequency of complications of sickle cell disease and factors reflecting the presence of hemolysis. Functional characteristics (including the New York Heart Association [NYHA] functional class and the 6-minute walk distance) and NT-proBNP levels were also similar in the two groups. However, patients in group 2 were significantly older and had a higher serum creatinine level than those in group 1.

Patients in group 3 (i.e., those with pulmonary hypertension, as confirmed on catheterization) differed markedly from patients without pulmonary hypertension. As compared with patients in groups 1 and 2, those in group 3 were significantly older and had significantly higher levels of lactate dehydrogenase and aspartate aminotransferase. In addition, the 24 patients with confirmed pulmonary hypertension also had a highly significant reduction in the 6-minute walk distance, a worse NYHA functional class, and a significantly increased NT-proBNP level, as compared with the other patients. The patients with pulmonary hypertension also had an increased frequency of leg ulcers, but there was no signifi- 


\begin{tabular}{|c|c|c|}
\hline Characteristic & $\begin{array}{l}\text { No. of Patients } \\
\text { Evaluated }\end{array}$ & Value \\
\hline Disease phenotype - no. (\%) & 385 & \\
\hline Hemoglobin SS & & $379(98)$ \\
\hline $\mathrm{S} \beta^{0}$ thalassemia & & $6(2)$ \\
\hline Age $-y r$ & 385 & $34 \pm 10$ \\
\hline Female sex — no. (\%) & 385 & $232(60)$ \\
\hline Body-mass index & 384 & $22 \pm 3$ \\
\hline Tricuspid regurgitant jet velocity $-\mathrm{m} / \mathrm{sec}$ & 385 & $2.3 \pm 0.4$ \\
\hline Blood pressure - $\mathrm{mm} \mathrm{Hg}$ & 377 & \\
\hline Systolic & & $118 \pm 16$ \\
\hline Diastolic & & $66 \pm 11$ \\
\hline Oxygen saturation — \% & 309 & $95 \pm 3$ \\
\hline History of vaso-occlusive crisis — no. (\%)† & 374 & $333(89)$ \\
\hline History of acute chest syndrome - no. (\%) & 380 & $239(63)$ \\
\hline History of stroke - no. (\%) & 375 & $19(5)$ \\
\hline History of hypertension — no. (\%) & 201 & $21(10)$ \\
\hline History of renal dysfunction — no. (\%) & 385 & $98(25)$ \\
\hline History of leg ulcers — no. (\%) & 377 & $67(18)$ \\
\hline History of priapism - no. (\% of men) & 153 & $55(36)$ \\
\hline Hydroxyurea therapy — (\%) & 385 & $90(23)$ \\
\hline Regular transfusion program — no. (\%) & 385 & $23(6)$ \\
\hline Hemoglobin - g/dl & 383 & $8.8 \pm 1.5$ \\
\hline White-cell count - no. $/ \mathrm{mm}^{3}$ & 384 & $9,700 \pm 4,900$ \\
\hline Platelet count - no. $/ \mathrm{mm}^{3}$ & 384 & $390,000 \pm 145,000$ \\
\hline Blood urea nitrogen $-\mathrm{mg} / \mathrm{dl}$ & 378 & $9.8 \pm 5.3$ \\
\hline Creatinine $-\mathrm{mg} / \mathrm{dl}$ & 385 & $0.73 \pm 0.26$ \\
\hline Lactate dehydrogenase — multiple of ULN & 368 & $1.9 \pm 0.9$ \\
\hline \multicolumn{3}{|l|}{ Bilirubin - mg/dl } \\
\hline Total & 382 & $3.45 \pm 3.16$ \\
\hline Direct & 380 & $0.64 \pm 0.46$ \\
\hline Aspartate aminotransferase $-U /$ liter & 383 & $40 \pm 20$ \\
\hline Alanine aminotransferase $-U /$ liter & 383 & $25 \pm 18$ \\
\hline Alkaline phosphatase $-U /$ liter & 380 & $94 \pm 48$ \\
\hline \multicolumn{3}{|c|}{$\begin{array}{l}\text { Plus-minus values are means } \pm S D \text {. Shown are the baseline characteristics of the patients who were evaluated accord } \\
\text { to the study protocol. The body-mass index is the weight in kilograms divided by the square of the height in meters } \\
\text { To convert the values for blood urea nitrogen to millimoles per liter, multiply by } 0.357 \text {. The creatinine clearance wa } \\
\text { determined with the use of the Cockcroft formula. To convert the values for creatinine to micromoles per liter, multi } \\
\text { by } 88.4 \text {. To convert the values for bilirubin to micromoles per liter, multiply by } 17.1 \text {. ULN denotes upper limit of th } \\
\text { normal range. } \\
\text { Taso-occlusive crisis was defined as pain related to sickle cell disease that required consultation at the emergency } \\
\text { department or hospitalization. }\end{array}$} \\
\hline
\end{tabular}

cant difference in the incidence of other disease The 24 patients with confirmed pulmonary hypercomplications. tension (group 3) had a higher tricuspid regurgi-

Hemodynamic findings in the 96 patients who tant jet velocity and significantly higher pulmounderwent catheterization are shown in Table 3. nary arterial systolic and diastolic pressures on 
catheterization than the 72 patients without confirmed pulmonary hypertension (group 2). Cardiac output was increased in both groups. Pulmonary vascular-resistance levels were significantly lower in group 2 than in group 3 .

According to the prespecified definitions, 11 patients had precapillary pulmonary hypertension, and 13 patients had postcapillary pulmonary hypertension. The severity of pulmonary hypertension in patients with precapillary pulmonary hypertension was usually mild or moderate, with a high cardiac output. Only 6 of the 11 patients with precapillary pulmonary hypertension had a pulmonary vascular resistance of $160 \mathrm{dyn} \cdot \mathrm{sec} \cdot \mathrm{cm}^{-5}$ or higher, the classic criterion for pulmonary arterial hypertension. ${ }^{24}$

\section{ASSESSMENT OF ECHOCARDIOGRAPHY AS A SCREENING TEST}

With a peak tricuspid regurgitant jet velocity of at least $2.5 \mathrm{~m}$ per second as a cutoff value for the selection of patients for catheterization, the positive predictive value of echocardiography for the detection of pulmonary hypertension was $25 \%$ (Fig. 1A in the Supplementary Appendix). In light of the updated guidelines for the use of echocardiography in screening for pulmonary hypertension, ${ }^{25}$ we retrospectively analyzed the performance of a cutoff value for a tricuspid regurgitant jet velocity of at least $2.9 \mathrm{~m}$ per second for the selection of patients for catheterization. On the basis of this higher cutoff value, the number of catheterizations would have been reduced from 96 to 22 , and the positive predictive value would have been increased from $25 \%$ to $64 \%$ (Fig. 1B in the Supplementary Appendix). However, with this higher threshold value, the false negative rate would have been at least $42 \%$.

We performed an exploratory analysis that used a combination of the tricuspid regurgitant jet velocity, the NT-proBNP level, and the 6-minute walk distance to select patients for catheterization (for details, see the Supplementary Appendix). For this analysis, test characteristics were determined on the assumption that patients with a tricuspid regurgitant jet velocity of $2.9 \mathrm{~m}$ or more per second or with a tricuspid regurgitant velocity between 2.5 and $2.8 \mathrm{~m}$ per second plus either an NT-proBNP level of at least $164.5 \mathrm{pg}$ per milliliter or a 6-minute walk distance of less than 333 m would undergo catheterization. On the basis of this approach, the positive predictive value was $62 \%$, and the false negative rate was at least $7 \%$.

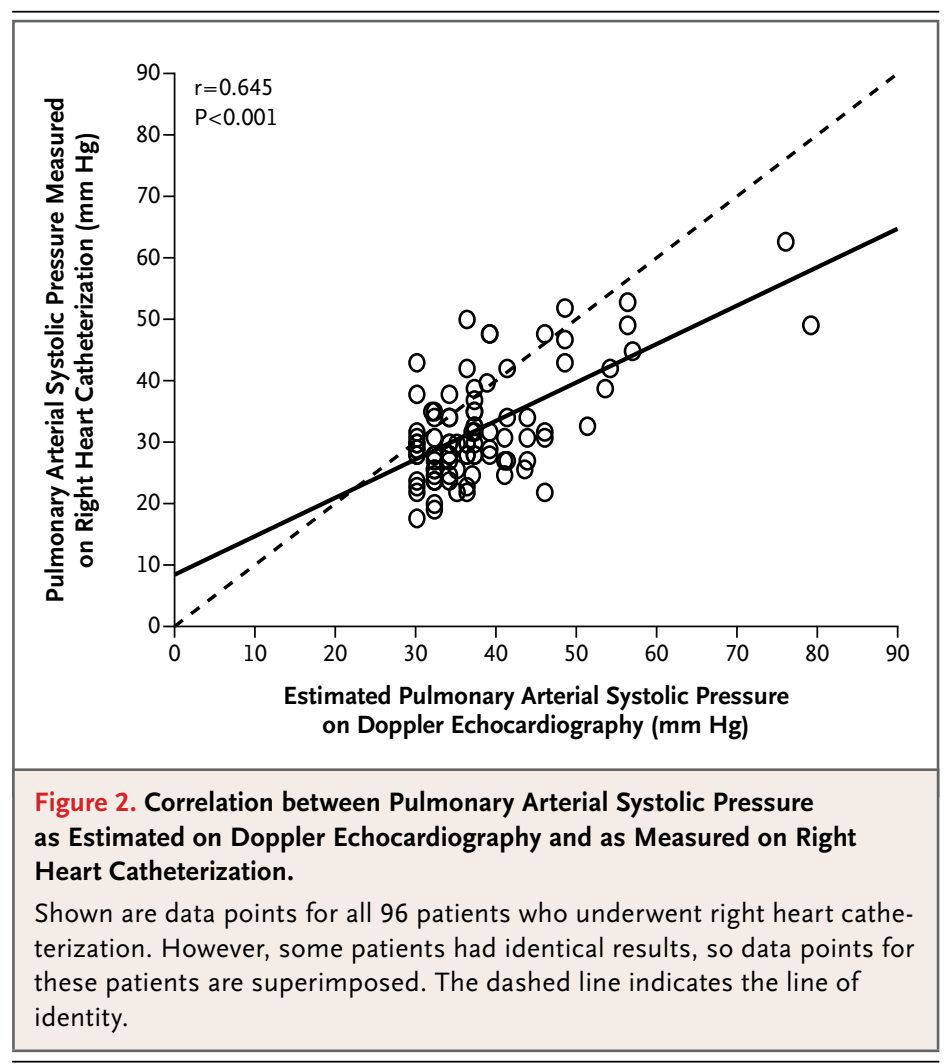

\section{ADVERSE EVENTS}

Three episodes of vasoocclusive crisis occurred in three patients shortly after catheterization, necessitating brief hospitalizations. There were no permanent sequelae related to these events.

During follow-up, 6 of 403 patients (2\%) died. Four of the 6 deaths occurred in association with a vasoocclusive crisis and acute chest syndrome. Of the patients who died, 1 was in group 1,1 was in group 2, 3 were in group 3, and 1 was in the group of 13 patients with a tricuspid regurgitant velocity of at least $2.5 \mathrm{~m}$ per second who declined to undergo right heart catheterization. Details regarding these deaths are provided in the Supplementary Appendix.

\section{DISCUSSION}

In this study of adults with sickle cell disease, the prevalence of a tricuspid regurgitant jet velocity of at least $2.5 \mathrm{~m}$ per second on echocardiography was $27 \%$, a rate consistent with those in other studies. ${ }^{9-12}$ In contrast, the prevalence of pulmonary hypertension that was confirmed on right heart catheterization was only $6 \%$. Approximately half the patients with confirmed pulmonary hy- 


\begin{tabular}{|c|c|c|c|c|}
\hline Characteristic & $\begin{array}{l}\text { Group } 1 \\
(\mathrm{~N}=\mathbf{2 8 9})\end{array}$ & $\begin{array}{c}\text { Group } 2 \\
(N=72)\end{array}$ & $\begin{array}{l}\text { Group } 3 \\
(\mathrm{~N}=24)\end{array}$ & P Value' \\
\hline Age $-y r$ & $33 \pm 9$ & $36 \pm 11 \div$ & $45 \pm 10 \div 0$ & $<0.001$ \\
\hline History of vaso-occlusive crisis — \% & 91 & 85 & 82 & 0.13 \\
\hline History of acute chest syndrome - \% & 60 & 68 & 78 & 0.72 \\
\hline History of leg ulcers — \% & 16 & 10 & 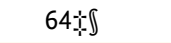 & $<0.001$ \\
\hline History of priapism — \% of men & 36 & 37 & 29 & 1.00 \\
\hline Hydroxyurea therapy — \% & 23 & 28 & 12 & 0.31 \\
\hline Hemoglobin - g/dl & $8.8 \pm 1.5$ & $8.7 \pm 1.6$ & $8.0 \pm 1.8$ & 0.42 \\
\hline Lactate dehydrogenase - multiple of ULN & $1.8 \pm 0.8$ & $1.8 \pm 0.8$ & $3.0 \pm 1.4 \div \delta$ & $<0.001$ \\
\hline Aspartate aminotransferase $-U /$ liter & $38 \pm 18$ & $42 \pm 17$ & $58 \pm 35 \div 0$ & $<0.001$ \\
\hline \multicolumn{5}{|l|}{ Bilirubin - mg/dl } \\
\hline Total & $3.4 \pm 2.6$ & $3.6 \pm 5.0$ & $3.5 \pm 2.0$ & 0.87 \\
\hline Direct & $0.64 \pm 0.47$ & $0.64 \pm 0.35$ & $0.94 \pm 0.90 \div \int$ & 0.02 \\
\hline Indirect & $2.8 \pm 2.4$ & $3.0 \pm 5.0$ & $2.6 \pm 1.6$ & 0.80 \\
\hline Creatinine $-\mathrm{mg} / \mathrm{dl}$ & $0.70 \pm 0.25$ & $0.84 \pm 0.24 \nmid$ & $0.83 \pm 0.35$ & 0.001 \\
\hline Alkaline phosphatase $-U /$ liter & $90 \pm 42$ & $93 \pm 47$ & $136 \pm 86 \div \delta$ & $<0.001$ \\
\hline Alanine aminotransferase $-U /$ liter & $25 \pm 18$ & $27 \pm 20$ & $25 \pm 9$ & 0.74 \\
\hline New York Heart Association class — \% & & & & $<0.001$ \\
\hline I or II & 94 & 93 & $62 \div$ & \\
\hline III or IV & 6 & 7 & $38 \div$ & \\
\hline Six-minute walk distance $-\mathrm{m} q$ & $520 \pm 88$ & $527 \pm 62$ & $404 \pm 94 \div \delta$ & $<0.001$ \\
\hline NT-proBNP $-p g / m l \|$ & $96 \pm 123$ & $95 \pm 77$ & $961 \pm 2067 ٪$ & $<0.001$ \\
\hline
\end{tabular}

* Plus-minus values are means \pm SD. Study groups were defined according to the values for tricuspid regurgitant jet velocity on Doppler echocardiography and the results of right heart catheterization. Patients in group 1 had a tricuspid regurgitant jet velocity of less than $2.5 \mathrm{~m}$ per second. Patients in group 2 had a tricuspid regurgitant jet velocity of at least $2.5 \mathrm{~m}$ per second without confirmed pulmonary hypertension on right heart catheterization. Patients in group 3 had a tricuspid regurgitant jet velocity of at least $2.5 \mathrm{~m}$ per second and confirmed pulmonary hypertension on right heart catheterization. The creatinine clearance was determined with the use of the Cockcroft formula. To convert the values for creatinine to micromoles per liter, multiply by 88.4. To convert the values for bilirubin to micromoles per liter, multiply by 17.1. NT-proBNP denotes N-terminal pro-brain natriuretic peptide, and ULN upper limit of the normal range.

$\uparrow P$ values are for overall comparisons of the three study groups and were calculated with the use of analysis of variance and post hoc Bonferroni tests for continuous variables and chi-square tests or Fisher's exact test with partition of type error risk for categorical variables.

$\leftarrow \mathrm{P}<0.025$ for the comparison with group 1 .

$\int P<0.025$ for the comparison with group 2.

9 The 6-minute walk distance was evaluated in 311 patients.

\|T The NT-proBNP level was evaluated in 275 patients.

pertension had precapillary pulmonary hypertension. If we had included the 47 patients with severe end-organ damage or clinical instability who underwent initial screening (Fig. 1), the prevalence of pulmonary hypertension might have been higher. Given the high prevalence of sickle cell disease in many regions, this complication may affect a large worldwide population.

The correlation between pulmonary arterial pressure as estimated on echocardiography and as measured on right heart catheterization was only moderately good in our study. When a threshold tricuspid regurgitant jet velocity of $2.5 \mathrm{~m}$ per second was used to define pulmonary hypertension, the positive predictive value of echocardiography was only $25 \%$. If pulmonary hypertension had been defined at a higher threshold, a tricuspid regurgitant jet velocity of $2.9 \mathrm{~m}$ per second, the positive predictive value of echocardiography would have improved, but several patients with 


\begin{tabular}{|c|c|c|c|c|c|}
\hline Variable & $\begin{array}{r}\text { Group } 2 \\
(\mathrm{~N}=72)\end{array}$ & $\begin{array}{l}\text { Group } 3 \\
(\mathrm{~N}=24)\end{array}$ & P Value $\hat{\dagger}$ & $\begin{array}{l}\text { Precapillary } \\
\text { Pulmonary } \\
\text { Hypertension } \\
(\mathrm{N}=11)\end{array}$ & $\begin{array}{l}\text { Postcapillary } \\
\text { Pulmonary } \\
\text { Hypertension } \\
(\mathrm{N}=13)\end{array}$ \\
\hline Patients who were evaluated (\% of all study patients) & 19 & 6 & & 3 & 3 \\
\hline Tricuspid regurgitant jet velocity $(\mathrm{m} / \mathrm{sec})$ & $2.7 \pm 0.2$ & $3.1 \pm 0.4$ & 0.001 & $3.1 \pm 0.5$ & $3.0 \pm 0.4$ \\
\hline Mean pulmonary arterial pressure $(\mathrm{mm} \mathrm{Hg})$ & $19 \pm 3$ & $30 \pm 6$ & $<0.001$ & $28 \pm 4$ & $32 \pm 7$ \\
\hline Pulmonary arterial systolic pressure $(\mathrm{mm} \mathrm{Hg})$ & $28 \pm 4$ & $44 \pm 7$ & $<0.001$ & $43 \pm 7$ & $45 \pm 8$ \\
\hline Pulmonary arterial diastolic pressure $(\mathrm{mm} \mathrm{Hg})$ & $12 \pm 3$ & $19 \pm 6$ & $<0.001$ & $15 \pm 5$ & $22 \pm 6$ \\
\hline Right atrial pressure $(\mathrm{mm} \mathrm{Hg})$ & $7 \pm 2$ & $10 \pm 6$ & $<0.001$ & $5 \pm 2$ & $13 \pm 5$ \\
\hline Pulmonary-capillary wedge pressure $(\mathrm{mm} \mathrm{Hg})$ & $11 \pm 3$ & $16 \pm 7$ & $<0.001$ & $10 \pm 3$ & $21 \pm 5$ \\
\hline Cardiac output (liter/min) & $8.4 \pm 2.1$ & $8.7 \pm 1.9$ & 0.60 & $8.2 \pm 16$ & $9.1 \pm 2.1$ \\
\hline Pulmonary vascular resistance $\left(\right.$ dyn $\left.\cdot \mathrm{sec} \cdot \mathrm{cm}^{-5} \rrbracket\right)$ & $72 \pm 26$ & $138 \pm 58$ & $<0.001$ & $178 \pm 55$ & $104 \pm 26$ \\
\hline New York Heart Association class (\%) & & & $<0.001$ & & \\
\hline I or II & 93 & 62 & & 55 & 69 \\
\hline III or IV & 7 & 38 & & 45 & 31 \\
\hline Six-minute walk distance $(\mathrm{m})$ & $527 \pm 62$ & $404 \pm 94$ & $<0.001$ & $406 \pm 107$ & $403 \pm 87$ \\
\hline NT-proBNP (pg/ml) & $95 \pm 77$ & $961 \pm 2067$ & $<0.001$ & $1443 \pm 2884$ & $479 \pm 557$ \\
\hline
\end{tabular}

* Patients in group 2 had a tricuspid regurgitant jet velocity of at least $2.5 \mathrm{~m}$ per second without confirmed pulmonary hypertension on right heart catheterization. Patients in group 3 had a tricuspid regurgitant jet velocity of at least $2.5 \mathrm{~m}$ per second and confirmed pulmonary hypertension on right heart catheterization. Data from patients in group 1 with a tricuspid regurgitant jet velocity of less than $2.5 \mathrm{~m}$ per second are not listed because they did not undergo right heart catheterization. NT-proBNP denotes N-terminal pro-brain natriuretic peptide.

$\dagger P$ values were calculated with the use of Student's t-test, except for the comparison of NT-proBNP levels, which was performed with the use of the Wilcoxon test, and the comparison of the functional New York Heart Association class, which was performed with the use of Fisher's exact test.

$¥$ Precapillary pulmonary hypertension is defined as a mean pulmonary arterial pressure of at least $25 \mathrm{~mm} \mathrm{Hg}$ and a pulmonary-capillary wedge pressure of $15 \mathrm{~mm} \mathrm{Hg}$ or less. Postcapillary pulmonary hypertension is defined as a mean pulmonary arterial pressure of at least $25 \mathrm{~mm} \mathrm{Hg}$ and a pulmonary-capillary wedge pressure of more than $15 \mathrm{~mm} \mathrm{Hg}$. Chronic thromboembolic pulmonary hypertension was ruled out on the basis of normal or nearly normal results on a ventilation-perfusion lung scan in all patients with precapillary pulmonary hypertension.

$\int$ Pulmonary vascular resistance was calculated as ([mean pulmonary arterial pressure-pulmonary-capillary wedge pressure $] \div$ cardiac output) $\times 80$.

pulmonary hypertension would not have been detected with such a threshold. We could not determine the false negative rate from our findings, since patients with a tricuspid regurgitant velocity of less than $2.5 \mathrm{~m}$ per second did not undergo right heart catheterization and some cases of pulmonary hypertension may not have been identified. Nonetheless, the use of the tricuspid regurgitant jet velocity on echocardiography as a single screening tool for the selection of patients for right heart catheterization does not appear to be ideal, whatever threshold is selected. There may be several reasons for the discrepancy between these two methods, including the imprecision of the echocardiographic measurement, inherent physiological variations in pulmonary hemodynamics, and the interval between echocardiography and catheterization (a median delay of 15 days).

As an alternative approach, we conducted an exploratory analysis to evaluate the use of tricuspid regurgitant velocity on echocardiography together with the NT-proBNP level and the 6-minute walk distance to select patients for right heart catheterization. In the resulting algorithm, right heart catheterization was recommended if the patient had a tricuspid regurgitant velocity of $2.9 \mathrm{~m}$ or more per second; for patients with a tricuspid regurgitant velocity between 2.5 and $2.8 \mathrm{~m}$ per second, right heart catheterization was recommended if the NT-proBNP level was at least 
164.5 pg per milliliter or the 6-minute walk distance was less than $333 \mathrm{~m}$. This approach would have been more accurate in selecting patients for right heart catheterization than using a tricuspid regurgitant velocity of $2.9 \mathrm{~m}$ per second alone. However, this algorithm is a provisional model derived directly from our own data. Given the limited number of patients in some of the subgroups in our study, and given the fact that this algorithm has not been validated in other patients with sickle cell disease, it cannot be considered suitable for general clinical application.

As has previously been reported, patients with sickle cell disease and precapillary pulmonary hypertension had a less marked increase in mean pulmonary arterial pressure, higher values of cardiac output, and lower levels of pulmonary vascular resistance than did patients with idiopathic pulmonary arterial hypertension. ${ }^{4}$ Despite having less severe hemodynamic impairment, these patients nonetheless had a clinically significant functional limitation, as assessed according to NYHA functional class (with $45 \%$ of patients in class III or IV) and a marked decrease in the 6-minute walk distance (mean, $406 \mathrm{~m}$ ). This poor exercise tolerance, despite only mild or moderate pulmonary hypertension, is probably multifactorial. Anemia, intrinsic cardiac disease, pulmonary vascular disease with oxygen desaturation, and musculoskeletal problems may all contribute to worsening of functional status.

The role of hemolysis in the pathogenesis of pulmonary hypertension in patients with sickle cell disease remains controversial. ${ }^{26}$ In our study, data regarding biologic markers of hemolysis were discordant. Hemoglobin and indirect bilirubin levels were similar in patients with confirmed pulmonary hypertension and in those without pulmonary hypertension. In contrast, we observed in patients with confirmed pulmonary hypertension significantly increased lactate dehydrogenase and aspartate aminotransferase levels, which may also be influenced by liver dysfunction. Further studies are needed to clarify the role of hemolysis in pulmonary hypertension in patients with sickle cell disease.

In our study, the overall rate of death was $2 \%$, which was significantly lower than the rate of $5.3 \%$ reported in a previous study by Gladwin et al., ${ }^{9}$ involving adults with sickle cell disease in the United States, despite similar mean follow-up periods in the two studies (26 months and 18 months, respectively). Such a discrepancy in mortality may be partially explained by our exclusion of patients with severe lung or liver disease or renal insufficiency. The French and U.S. study populations also differed with respect to the frequency of vascular complications, which occurred less often in our patients. Lastly, patients in the U.S. study were recruited through community outreach programs and advertising campaigns, whereas our patients were recruited from referral centers.

In conclusion, in a study of adult outpatients with stable sickle cell disease, we found that the prevalence of pulmonary hypertension, as detected on initial echocardiographic screening and confirmed by right heart catheterization, was $6 \%$. Echocardiographic evaluation alone with the use of the tricuspid regurgitant velocity as a threshold criterion had a low positive predictive value for pulmonary hypertension. The optimal approach for screening such patients for right heart catheterization remains uncertain.

Supported by the French Ministry of Health and the Delegation for Clinical Research of the Assistance Publique-Hôpitaux de Paris.

Disclosure forms provided by the authors are available with the full text of this article at NEJM.org.

We thank Dr. David Montani for his assistance in the preparation of the manuscript.
REFERENCES

1. Sutton LL, Castro O, Cross DJ, Spencer JE, Lewis JF. Pulmonary hypertension in sickle cell disease. Am J Cardiol 1994; 74:626-8.

2. Haque AK, Gokhale S, Rampy BA, Adegboyega P, Duarte A, Saldana MJ. Pulmonary hypertension in sickle cell hemoglobinopathy: a clinicopathologic study of 20 cases. Hum Pathol 2002;33:1037-43.

3. Castro O, Hoque M, Brown BD. Pulmonary hypertension in sickle cell disease: cardiac catheterization results and survival. Blood 2003;101:1257-61.
4. Anthi A, Machado RF, Jison ML, et al. Hemodynamic and functional assessment of patients with sickle cell disease and pulmonary hypertension. Am J Respir Crit Care Med 2007;175:1272-9.

5. Humbert M, Sitbon O, Simonneau G. Treatment of pulmonary arterial hypertension. N Engl J Med 2004;351:1425-36. 6. Simonneau G, Robbins IM, Beghetti $\mathrm{M}$, et al. Updated clinical classification of pulmonary hypertension. J Am Coll Cardiol 2009;54:Suppl:S43-S54.

7. Galiè $N$, Hoeper MM, Humbert $M$, et al. Guidelines for the diagnosis and treatment of pulmonary hypertension. Eur Respir J 2009;34:1219-63.

8. Galiè N, Hoeper MM, Humbert $M$, et al. Guidelines for the diagnosis and treatment of pulmonary hypertension: The Task Force for the Diagnosis and Treatment of Pulmonary Hypertension of the European Society of Cardiology (ESC) and the European Respiratory Society (ERS), endorsed by the International Society of Heart and Lung Transplantation (ISHLT). Eur Heart J 2009;30:2493-537. 
9. Gladwin MT, Sachdev V, Jison ML, et al. Pulmonary hypertension as a risk factor for death in patients with sickle cell disease. N Engl J Med 2004;350:886-95. 10. Ataga KI, Moore CG, Jones S, et al. Pulmonary hypertension in patients with sickle cell disease: a longitudinal study. Br J Haematol 2006;134:109-15.

11. De Castro LM, Jonassaint JC, Graham FL, Ashley-Koch A, Telen MJ. Pulmonary hypertension associated with sickle cell disease: clinical and laboratory endpoints and disease outcomes. Am J Hematol 2008; 83:19-25.

12. Gordeuk VR, Sachdev V, Taylor JG, Gladwin MT, Kato G, Castro OL. Relative systemic hypertension in patients with sickle cell disease is associated with risk of pulmonary hypertension and renal insufficiency. Am J Hematol 2008;83:15-8. 13. Badesch DB, Champion HC, Sanchez $\mathrm{MA}$, et al. Diagnosis and assessment of pulmonary arterial hypertension. J Am Coll Cardiol 2009;54:Suppl:S55-S66.

14. Hachulla E, Gressin V, Guillevin L, et al. Early detection of pulmonary arterial hypertension in systemic sclerosis: a French nationwide prospective multicenter study. Arthritis Rheum 2005;52:3792-800.

15. Sitbon O, Lascoux-Combe C, Delfraissy JF, et al. Prevalence of HIV-related pulmonary arterial hypertension in the current antiretroviral therapy era. Am J Respir Crit Care Med 2008;177:108-13.
16. Lapa M, Dias B, Jardim C, et al. Cardiopulmonary manifestations of hepatosplenic schistosomiasis. Circulation 2009; 119:1518-23.

17. Quiñones MA, Otto CM, Stoddard M, Waggoner A, Zoghbi WA. Recommendations for quantification of Doppler echocardiography: a report from the Doppler Quantification Task Force of the Nomenclature and Standards Committee of the American Society of Echocardiography. J Am Soc Echocardiogr 2002;15:167-84. 18. Lang RM, Bierig M, Devereux RB, et al. Recommendations for chamber quantification: a report from the American Society of Echocardiography's Guidelines and Standards Committee and the Chamber Quantification Writing Group, developed in conjunction with the European Association of Echocardiography, a branch of the European Society of Cardiology. J Am Soc Echocardiogr 2005;18:1440-63. 19. Saxena N, Rajagopalan N, Edelman K, López-Candales A. Tricuspid annular systolic velocity: a useful measurement in determining right ventricular systolic function regardless of pulmonary artery pressures. Echocardiography 2006;23:750-5. 20. Berger M, Haimowitz A, Van Tosh A, Berdoff RL, Goldberg E. Quantitative assessment of pulmonary hypertension in patients with tricuspid regurgitation using continuous wave Doppler ultrasound. J Am Coll Cardiol 1985;6:359-65.
21. Kircher BJ, Himelman RB, Schiller NB. Noninvasive estimation of right atrial pressure from the inspiratory collapse of the inferior vena cava. Am J Cardiol 1990; 66:493-6.

22. Lanzarini L, Fontana A, Lucca E, Campana C, Klersy C. Noninvasive estimation of both systolic and diastolic pulmonary artery pressure from Doppler analysis of tricuspid regurgitant velocity spectrum in patients with chronic heart failure. Am Heart J 2002;144:1087-94.

23. Breiman LFJ, Olshen RA, Stone CJ. Classification and regression trees. Belmont, CA: Wadsworth, 1984.

24. Barst RJ, McGoon M, Torbicki A, et al. Diagnosis and differential assessment of pulmonary arterial hypertension. J Am Coll Cardiol 2004;43:12 Suppl S:40S-47S.

25. Rudski LG, Lai WW, Afilalo J, et al. Guidelines for the echocardiographic assessment of the right heart in adults: a report from the American Society of Echocardiography endorsed by the European Association of Echocardiography, a registered branch of the European Society of Cardiology, and the Canadian Society of Echocardiography. J Am Soc Echocardiogr 2010;23:685-713.

26. Bunn HF, Nathan DG, Dover GJ, et al. Pulmonary hypertension and nitric oxide depletion in sickle cell disease. Blood 2010; 116:687-92.

Copyright @ 2011 Massachusetts Medical Society.

EARLY JOB ALERT SERVICE AVAILABLE AT THE NEJM CAREERCENTER

Register to receive weekly e-mail messages with the latest job openings that match your specialty, as well as preferred geographic region, practice setting, call schedule, and more. Visit the NEJM CareerCenter at NEJMjobs.org for more information. 